\title{
Commentary
}

Theme: Recent Advances on Drug Delivery Systems for Viral Infections

\section{The Impact of Science-Unbased Measures Against COVID-19 in Clinical Decision-Making Process}

\author{
João Vitor Cândido Pimentel, ${ }^{1,2}$ (1) Thaíse Duarte Onofre Sabiá e Silva, ${ }^{1}$ \\ Ana Beatriz Tavares Filgueiras, ${ }^{1}$ and Modesto Leite Rolim Neto ${ }^{1}$
}

KEY WORDS: pseudoscience; clinical decision-making; COVID-19.

Dear Editor,

We have read the review article entitled "Diagnostic and Treatment Strategies for COVID-19" produced by Jamshaid H. and colleagues, published online in AAPS PharmSciTech on August 03, 2020. We wish best regards to the authors because of the useful kind of information approached in this work. It systematically reviewed and summarized the main approaches used to manage SARS-CoV-2 infection until August 2020, serving as a possible guide to clinical decisionmaking process against COVID-19 all around the world (1). Nevertheless, as this work also states, several measures to deal with this disease lack scientific evidence.

COVID-19 is an infective viral disease that caused almost one million deaths since its spread, with more than 33 million confirmed cases throughout the globe (2), until 28 September 2020. The urging search for COVID-19's prevention and management, and the absence of science-based information regarding several issues about this disease, is giving the opportunity for pseudoscience and science-unbased clinical decision-making process to grow as sources of socially acceptable measures against this disease (3), also adopted by many clinicians around the world. Scientific-unbased information fights against the real effort made to manage COVID19 (4), once the spread of this kind of (mis)information creates the wrong sense of being "protected" or "treated" against a still little known disease.

Scientific-unbased information regarding COVID-19 treatments are especially propagated by traditional healers or politicians who do not have the necessary comprehension about

Guest Editor: Claudio Salomon

${ }^{1}$ School of Medicine, Universidade Federal do Cariri - UFCA, Divino Salvador Street, 284, Alto do Rosário District, Barbalha, Ceará, Brazil.

${ }^{2}$ To whom correspondence should be addressed. (e-mail: jvcpimentel@gmail.com)

2 :. disease processes (4). One can cite the extensive discussion regarding the use of hydroxychloroquine (HCQ) against COVID-19, defended by Donald Trump, the US president, or Jair Bolsonaro, Brazil's president. In June 2020, Arshad S. and colleagues published an observational study that states that HCQ with or without azithromycin (AZT) is effective against COVID-19 (5). A non-aware clinician that reads this article could begin to prescribe HCQ for COVID-19 patients, without taking into consideration that this was a retrospective, nonrandomized, and non-blinded study, and that more steroids were given to $\mathrm{HCQ}$ and $\mathrm{HCQ}+\mathrm{AZT}$ groups compared to the group that received neither HCQ nor AZT. Steroids-dexamethasone specifically - are now a well-known class of medication that can lower 28-day mortality in COVID-19 patients who are receiving any kind of oxygen respiratory support (6). Otherwise, there is a multicenter, randomized, open-label, three-group, controlled trial showing that HCQ, with or without AZT, in patients receiving a maximum of 4 liters per minute of supplemental oxygen does not improve clinical status at 15 days of treatment, compared to standard care (7). Several other medications, like ivermectin, carrimycin, and nitazoxanide, are claimed to treat COVID-19, but data regarding this effect lack scientific evidence (1).

It is expected that this crisis could bring a wellwidespread recognition that tolerating science-unbased measures against any disease can cause real harm (3), once clinical decision-making process based on this kind of source can lead society-especially clinicians-to adopt treatment strategies that do not have an expected end.

\section{REFERENCES}

1. Jamshaid $\mathrm{H}$, et al. Diagnostic and treatment strategies for COVID-19. AAPS PharmSciTech. 2020;21(6). https://doi.org/ 10.1208/s12249-020-01756-3. 
2. World Health Organization. WHO coronavirus disease (COVID19) dashboard [Internet]. WHO, 2020 [Accessed 28 September 2020]. Available from: https://covid19.who.int/

3. Caulfield T. Pseudoscience and COVID-19 - we've had enough already [Internet]. Nature, 2020 []. Available from: https:// www.nature.com/articles/d41586-020-01266-z. DOI: https:// doi.org/10.1038/d41586-020-01266-z.

4. Desta TT, Mulugeta T. Living with COVID-19-triggered pseudoscience and conspiracies. Int J Public Health [Internet]. 2020;65(6):713-4. https://doi.org/10.1007/s00038-02001412-4.

5. Arshad S, Kilgore P, Chaudhry ZS, Jacobsen G, Wang DD, Huitsing $\mathrm{K}$, et al. Treatment with hydroxychloroquine, azithromycin, and combination in patients hospitalized with
COVID-19. Int J Infect Dis. 2020;97:396-403. https://doi.org/ 10.1016/j.ijid.2020.06.099.

6. The RECOVERY Collaborative Group. Dexamethasone in hospitalized patients with Covid-19 - preliminary report. N Engl J Med. 2020:1-11. https://doi.org/10.1056/NEJMoa2021436.

7. Cavalcanti AB, Zampieri FG, Rosa RG, Azevedo LCP, Veiga VC, Avezum A, et al. Hydroxychloroquine with or without azithromycin in mild-to-moderate Covid-19. N Engl J Med. 2020. https://doi.org/10.1056/NEJMoa2019014.

Publisher's Note Springer Nature remains neutral with regard to jurisdictional claims in published maps and institutional affiliations. 